\title{
A Rica Fauna da Política Industrial e a sua Nova Fronteira
}

Antonio BarrosdeC astro

Professor Titular do Instituto de Economia da UFRJ

RESUM O

0 artigo apresenta três abordagens da política industrial.

A primeira deriva, diretamente, da teoria econômica, etem por referência central anoção de "fal has demercado" - a serem corrigidas mediante política industrial.

A segunda, nasce das frustrações com o desenvolvimento de nações, regiões ou setores. Reúne, em suma, esforços visando a (rápida) superação do atraso acumulado.

A terceiraeúltimatem por referência contextos em queas empresas são (ou começam a ser) capazes de competir via inovações, no sentido amplo da pal avra. N este caso ganham crescente importância funções corporativas como o P\& D, o design eo marketing. Às políticas cabeapoiar as empresas de variadas formas, para que possam lançar mão destas armas da competição.

$\mathrm{N}$ ão étratada a importante e complexa temática das políticas de infra-estrutura. U ma brevíssima menção ao tema será no entanto feita, tendo por objeto a "infra-estrutura da inovação", questão primordial no terceiro grupo de políticas objeto deste trabal ho.

0 trabalho conclui com uma referência ao caso brasileiro, concebido como um caso peculiar de reestruturação pós-abertura, que crescentemente requer políticas do terceiro tipo aqui examinado.

Palavras-Chave | Política Industrial; Falhas de M ercado; Catch up; Reestruturação; Inovação

CódigosJeL $\mid$ OO,L52 
ABSTRACT

Thearticlepresents threeapproachesto industrial policy.

Thefirst derives directly from the economic theory and has its central reference in the notion of "market failures" - to becorrected through industrial policy.

Thesecond originatesfrom frustationswith the development of nations, regi onsor sectors. In short, it gathersup effortsaiming at the (quick) surmounting of accumulated backwardness.

Thethird and last one refers to contexts in which companies are (or begin to be) ableto compete, via innovation lato sensu. In this case, gain growing importance corporativefunctions such asR \& D , design and marketing. Thepolicies roleis to support companies in diverseways, so they can make use of these competition weapons.

It is not addressed the importat and complex theme of infra-structure policies, theme wich, nevertheless will be briefly mentioned in view of "the infra-structure of innovation", a fundamental question in the set of policies addressed in the work.

Thepaper concludes with a referenceto theB razilian case, conceived as a peculiar case of post-opening restructuring that increasingly callsfor policies of thethird kind above examined.

Keywords I Industrial Policy; M arket Failures; Catch up; Restructuring; Innovation JEL-CODES $\quad 00$, L52

\section{Política industrial para a correção das falhas de mercado}

D eacordo com a corrente central da teoria econômica, doisfatos podem afastar uma economia demercado da posição de equilíbrio geral - situação em que coincidiriam, plenamente, 0 interesse privado e 0 interesse público. 0 primeiro se verifica ali onde o mercado apresenta "falhas" que 0 afastam da condição de concorrência perfeita, o segundo decorreria da intervenção dos poderespúblicos.

D ado o queprecede, as políticas industriais(nesta primeiraacepção), teriam a sua razão de ser na correção das fal has demercado, de maneira a reconciliar o interesse privado com o interesse social. Como sedaria, porém, esta reconciliação? M ediante a alteração, politicamente decidida, dos preços relativos com que se defrontam osagenteseconômicos. Tarifasaduaneiras maioresou menores, juros 
subsidiados, isenção tributária, eassunção (socialização) do risco privado, seriam exemplos deinterferências no sistema de preços visando alterar (e, supostamente, corrigir) os sinais demercado e, por conseguinte, as decisões privadas.

A existência de economias externas, bem como de desigualdades ou assimetria no acesso a informações são casos típicos de falhas de mercado, a serem corrigidas por intervenções capazes de restaurar as condições adequadas à busca, pelos agentes econômicos, do equilíbrio geral. Para tanto seria, contudo, necessário contar com órgãos públicos - e tecnocratas - capazes de perceber e avaliar as divergências e distorções, e dimensionar as correções necessárias ao restabelecimento da coincidência entreo ótimo privado eótimo para a coletividade.

D ois breves comentários serão aqui apresentados, a respeito do queacaba deser dito. ${ }^{1}$

0 primeiro é que ainda quando se conclua pela presença de desvios do tipo aqui focalizado, a perspectiva centrada nas falhas de mercado não necessariamenterecomenda a real ização deinterven ções corretivas. Para entendêlo convém lembrar, antes de mais nada, as dificuldades técnicas a serem enfrentadas na avaliação, tanto dos desvios, quanto do necessário à sua compensação. Por outro lado, existem também problemas inerentes à ação pública, ou, melhor dito, à gestão do interesse coletivo. Assim, por exemplo, podem ocorrer fenômenos conhecidos como "captura" deórgãos públicos por parte de interesses privados. H averia também que reconhecer a miopia usual (curto-prazismo) da ação política, eas possibilidades declientelismo, nepotismo, etc. N uma palavra, énecessário ter em conta as possíveis "fal has degoverno". E se as falhas a serem introduzidas pelo governo excederem os desvios endogenamentegerados pelo mercado, érazoável concluir pela não intervenção.

A segunda observação é de ordem prática. N os anos 1980 e 1990 prevaleceu uma atitude fortemente crítica em relação à competência eisenção dos órgãos públicos. Se combinarmos este pessimismo no tocante à ação dos poderes públicos, com a prevalência- especialmentenos países subdesenvolvidos - de imensas disparidades sociais (e portanto de óbvias razões para expandir os gastos com educação e saúde), chega-se a conclusões marcadamente restritivas faceàspolíticasindustriais.

\footnotetext{
Uma visão geral desta temática é apresentada em Bhagwati (1971). Visões críticas da perspectiva tradicional podem ser encontradas em Chang (1994) e Metcalfe (1994).
} 
A rigor, dada a forte suspeição, especialmente no tocante ao estadoprodutor, passou-se na prática a recomendar (além de medidas destinadas a melhorar 0 ambientemacroeconômico), exclusivamente, políticas voltadas para 0 aprimoramento da qualidade dos fatores disponíveis (políticas horizontais). Com isto, as versões menos críticas da política industrial (filiadas a esta visão), passaram a recomendar extrema moderação no seu uso - mesmo diante de comprovadasfalhas demercado. E além disto, claro, sempreequando aintervenção se justificasse, estrita observância das severas regras introduzidas pela O M C.

Em diversos países isto acarretou uma ostensiva ruptura com o passado, caracterizado pelo predomínio da família depolíticas industriaistotalmentediversa, a seguir caracterizada.

\section{Política industrial como política "de resultados"}

A segunda abordagem nasce da comparação entreexperiências históricas. Por contraste com a primeira visão - que deriva de uma determinada concepção teórica de como opera a economia, em condições de concorrência perfeita e mercados completos - esta segunda matriz das políticas industriais surge da frustração com a situação existente. 0 enquadramento histórico é aqui imprescindível, mas a reflexão pode, em princípio, levar ao queN elson eW inter (1982) propuseram chamar de "teoria apreciativa". Podemos genericamentea elas nos referir, como políticas industriais "de resultados".

É importantelembrar que, para os adeptos da primeira visão, as diferenças entre os níveis médios de renda das economias integradas ao mercado mundial tendem areduzir-se: éa teseda convergência. A história pareceindicar, no entanto, que grandes diferenças, uma vez surgidas - e ressalvadas exceções - tendem a permanecer e até mesmo a ampliar-se. ${ }^{2} \mathrm{E}$ isto parece haver se comprovado, mais que nunca, no último quarto de século.

Alguns poderiam ser tentados a dizer que ampliando-se suficientemente o conceito de falhas de mercado, seria possível entender os casos de não

\footnotetext{
2 Casos excepcionais de rápida diminuição da distância serão a seguir referidos. A Argentina, de sua parłe, é também uma exceção: de sinal invertido, no entanto. Com efeito, em 1910 o país contava com uma renda per capita equivalente a $75 \%$ da norte-americana!
} 
convergência. Esta parece ser, no entanto, uma fal sa pista. Afinal, quando nos referimos a falhas de mercado estamos falando de circunstâncias capazes de provocar o afastamento do equilíbrio geral. No terreno em que estamos ingressando, no entanto, encontram-sefenômenos obviamente não redutíveis a desvios de um suposto ótimo. Trata-se de outras realidades, em maior ou menor medida dotadas de sua própria consistência interna.

D efato, os desequilíbrios regionais persistentes (como o do sul dal tália), o atraso e a pobreza de certas nações, e até mesmo a decadência crônica de certas indústrias nos países desenvolvidos são problemas econômicos profundamente entranhados no tecido socioeconômico, e sujeitos à ação de mecanismos de reprodução das características (e dificuldades). Em tais casos, sem que grandes e profundas mudanças - capazes de alterar referências, condutas, e a própria visão do futuro - venham a ocorrer, dificilmente se escapa ao círculo de ferro das características que se confirmam ese realimentam. E é aqui que pode entrar em cena um tipo muito peculiar e historicamente importante de políticaindustrial.

R efiro-me a esforços concentrados visando a promoção de autênticos saltos históricos, como também à construção ou reconstrução de setores ou regiões. N os casos clássicos de "emparelhamento" (catch up), na Europa do II pós-Guerra, emesmo no caso dosEstadosU nidosfrenteà brutal pressão exercida pela competição japonesa nos anos 1980, variantes fortes ou fracas desta família depolíticasindustriais estiveram presentes. $\mathrm{N}$ a brevereferência a seguir, contudo, apenas a hipótese do catch up histórico será considerada.

A grande pergunta para as economias (setores ou regiões) que ficaram para trás é: existem maneiras de se avançar rapidamente, recuperando-se 0 tempo e o terreno perdidos? 0 u, vista a questão por outro ângulo: é possível apropriar-se, deliberada e generalizadamente, de soluções encontradas e desenvolvidas nas economias mais avançadas?

A resposta não pode ser outra senão um vigoroso sim.

Antes de mais nada, porque isto já foi diversas vezes feito. Atalhos históricos foram e têm sido encontrados. No passado, pela Alemanha, e o 
Japão. Recentemente, pela C oréia; eno presente, pela minúscula Cingapurae a gigantesca C hina. N este sentido, foram em vão os esforços realizados por tantos scholars para negar a importância e a eficácia das especialíssimas instituições, políticas e expedientes de que lançaram mão estes países, para promover o emparelhamento. Só o que resta aos recalcitrantes é aceitar as evidências, ponderando que para tanto foram necessárias condições "especiais". O corre, porém, que a criação de soluções especiais, capazes de substituir os requisitos clássicos do desenvolvimento, constitui um dos pontos de partida dostrabalhos de Gerschenkron (1966), patrono da temática da industrialização retardatária eacelerada.

Além disto, porque diversas soluções lançadas pelos mais avançados, especialmente no campo tecnológico, após devidamente trabal hadas e desenvolvidas, tornam-se soluções "superiores" - no sentido de que poupam capital, trabalho, bem como, possivelmente, tempo e energia! Chegamos, assim, a uma complexa questão: por queas soluções superiores não são adotadas nas economias e regiões que permanecem atrasadas? $\mathrm{O} u$, vista a questão de outra maneira, como é possível ter êxito no amplo transplantede conhecimento das economias mais avançadas para as que ficaram para trás? ${ }^{3}$

A resposta a estas indagações obviamente transcende 0 objetivo deste artigo. 0 tema será, no entanto, aqui tocado, dado o interesse em levar adiante a classificação das políticas industriais. Com esteintuito, admitamos departida que muitas soluções superiores são efetivamente adotadas no meio ambiente atrasado, de forma espontânea, e guiada pelos sinais de mercado. Esta é, aliás uma razão para que países relativamente atrasados (quando não contidos ou travados) cresçam mais rápido que os países avan çados. M ais precisamente, e na terminologia de G erschenkron, esta seria uma das "vantagens do atraso". Acontece, porém, que a difusão de soluções superiores é freqüentemente impedida ou restringida.

A razão fundamental para que diversas soluções superiores não se difundam nos países atrasados é que elas requerem, especialmente nestes contextos, muito mais do que 0 automatismo do mercado. Refiro-me, sobretudo, a decisões que supõem grandes e poderosos atores, exigem uma

3 Uma ambiciosa tentativa de enfrentamento desta temática pode ser encontrada em Amsden (2001). 
base diversificada e robusta de serviços (precária ou inexistente nas nossas economias), além do compartilhamento de conhecimentos que foram sendo criados com o avanço das novas soluções.

A conjugação de decisões em al guma medida interdependentes, a serem, no entanto, tomadas, de forma praticamente simultânea (e em terrenos marcadamente díspares), requer al gum tipo de coordenação extramercado. Referimo-nos, em síntese, a um tipo de coordenação antecipada, implicando os atores ou candidatos a atores envolvidos em mudanças que só o futuro dirá se tiveram sucesso.

N o mercado, por contraste, a coordenação vai brotando à medida que as empresas e pessoas vão respondendo aos preços - sem ter em conta as conseqüências disto sobre os demais. Trata-se de uma coordenação tácita, e realizada de maneira ex post, via prêmio e punição. Q uando, porém, há que combinar previamente os programas de ação e inclusive, não raro, constituir os próprios atores, a coordenação énecessariamente de outra natureza. A bem dizer a coordenação de atores grandes e complexos, para quetomem decisões interdependentes, anteci padamente aos resultados e conseqüências esperadas, não pode ser cobrada do mercado. N uma palavra, isto escapa à sua natureza e função precípua: integrar decisões anônimas e difusas, através de uma coordenação inconscientee imperceptível.

N o tipo de coordenação ex ante a que estamos aqui nos referindo é aliás preciso contar com atores radicalmente diferentes das firmas que asseguram, na economia convencional, o funcionamento surdo eincremental do mercado. M as o problema, como já foi anteriormente sugerido, não é só de combinação visando a apropriação de avanços já consagrados em outros contextos. É, sobretudo, de absorção ampla de conhecimentos. E isto pode, em princípio, rapidamente ser feito, porque o conhecimento vem, em grande medida, embutido nos equipamentos e insumos. Basta, pois, que técnicose trabal hadores se empenhem em desenvolver as suas próprias práticas e rotinas operacionais. 0 problema, insisto, é quem promove, ou, melhor, quem combina e quem executa as transformações. E este desafio praticamente só podeser enfrentado por grandes estruturas estáveis, sejam elas grandesempresasâncora, públicas ou privadas (como tem sido o caso dos novos investimentos automobilísticos no Brasil); poderes públicos; ou outros atores coletivos. $\mathrm{O}$ u 
seja, tudo menosafirma representativa do "capitalismo pessoal" dequefala Lazonik (1994), referindo-seà experiência manchesteriana.

0 mercado, por si, não é em suma capaz de alavancar mudanças que requerem capacidade de combinar, previamente, decisões mutuamente dependentes. Este, aliás, seria o preço a pagar (como não negaria, segundo creio, 0 perspicaz $\mathrm{H}$ ayek) pelasvantagens oferecidas pela coordenação espontânea, no vasto domínio em queela podeeficazmente ser praticada. ${ }^{4}$

Voltemos às experiências de emparelhamento, agregando algumas observaçõesúteisà apresentação, a seguir, da terceira família de políticas voltadas para o chamado lado real da economia.

A segunda concepção tem em comum com a primeira, o fato de que age (também) através da alteração de preços relativos. $M$ as ao invés de limitar-se a alterar preços relativos, visando promover a convergência entreganhos privadose ganhos sociais, seu objetivo éa construção ou recuperação de condições semel hantes àsque podem ser encontradasnaseconomiaslíderes. Trata-se, pois, concretamente, de replicar no País ou região atrasada, a capacidade de produzir existente entre os maisavançados.

Em contextos relativamente defasados, mas com capacidade de articular decisões - e determinação de fazêlo -, tem se revelado um projeto não apenas exeqüível, mas, em certoscasos, excepcionalmentebem-sucedido. A história avança então a saltos - sendo que os referidos saltos usualmente trazem consigo novos setores ou blocos deatividades. Estamosaqui, pois, no império da mesoeconomia (Vartiainen, 1999).

Inicialmente, pelo menos, a noção de otimização permanece, na segunda acepção, restrita ao campo da engenharia. As máquinas como os insumos devem "render" o ótimo técnico, anunciado nos manuais. Em outras palavraso objetivo primordial é mesmo produzir, fazendo-se para tanto bom uso das instalações e demaisrecursos.

A empresa é portanto vista, no caso, como unidade produtiva - o que

4 Sobre o que pode e o que não pode ser coordenado pelo mercado ver Richardson (1997). 
parece uma obviedade, mas revela escolhas deenormerelevância (como serámais adianteindicado). Elas competem, essencialmente, via crescimento, expandindose mais ou menos do que a média do setor: numa economia dominada pela cultura mesoeconômica, esta parece ser a métrica adequada.

A esta competição tende, no entanto, a sobrepor-se uma outra, que deve também ser apontada. Trata-se da disputa entre os órgãos públicos (ministérios, empresas públicas, etc.) a cargo dos programas. E aqui a competição éobviamente política - como no caso recente da corrida entre os governos de estados, para implantar fábricas montadoras de automóveis.

Essencialmente, no entanto, o esforço sedestina a introduzir rupturas, cujo real significado só poderá ser efetivamente avaliado muito mais adiante. Além disto, asseguradaa capacidade de produzir, a competição com o exterior éfacilitada (ou mesmo garantida) mediantetarifas protetoras, subsídiosà exportação e outros "preços fora do lugar" (a expressão édeAmsden). N ão é preciso sublinhar quea alteração de preços não visa aqui o reencontro do ótimo (como no primeiro tipo depolíticas industriais), esim a transformação da economia em direção aos perfis produtivoscaracterísticos daseconomias maisavançadas. Finalmentenão épreciso tampouco insistir no fato de que cada setor traz consigo demandas específicas no tocantea infra-estrutura ea conhecimentos especializados.

Estamosagora em condições detransitar para a terceirafamília de políticas.

\section{Política industrial como resíduo, e a nova fronteira de políticas}

N a expressão dePenrose (1959) as empresas derivam "serviços produtivos" dos recursos a sua disposição. Seguramente estes serviços produtivos podem e mesmo tendem a mudar com o tempo, e com a evolução do conhecimento.

Admitamos que os usos que as empresas podem fazer das instalações, máquinas e equipamentos - bem como dos conhecimentos acumulados pelos que nela trabalham - oferecem-lhes, a cada momento, um conjunto de possibilidades. 0 empreendedorismo de seus dirigentes deve então explorálas, tendo um olho cravado nasoportunidades perceptíveisno mercado.

Se isto já era assim ao tempo em que Penrose lança sua obra seminal, com mais razão passou a sêlo contemporaneamente. O u seja, sua abordagem se 
torna maissignificativa emaisrelevante, à medida queo trabal hador vai deixando de ser percebido como "força de trabalho", passando a integrar equipes e, não raro, a participar da tomada de decisões. Ajuda ainda a ampliar o espectro de possi bilidades das empresas, a crescente versatilidadedos equipamentos. Por fim, a agilidade conferida pelas modernas técnicas de gerenciamento - e o próprio acirramento da competição - , contribuem para o ingresso num tipo deeconomia marcado pela presença de empresas relativamenteflexíveise versáteis. C onfigurase desta forma uma economia que pode ser caracterizada como "decisão intensiva".

Tendo o que precede como pano defundo, introduzimosa seguir aterceira e última família de políticas voltadas para o chamado lado real da economia. Advertimos que o foco da análise serão as economias que já lograram construir uma estrutura industrial razoavelmente moderna, sem, contudo, equiparar-seà condição de economias desenvolvidas. Este estreitamento de foco visa, como veremos, preparar o terreno para o tratamento do caso brasileiro na parte final destetrabalho.

A terceirafamília de políticastem em comum com a segunda (queengloba as "políticas de resultados"), o fato de que o seu objeto étambém a mudança, ou transformação. 0 u seja, não se trata de corrigir sinais demercado (preços), para que os agentes privados reencontrem (como na visão centrada no combate às falhas de mercado) a assignação ótima dos recursos existentes na economia. M as o tipo demudança perseguido por esta abordagem difereem muitoseimportantes sentidos, das transformações buscadas pelas políticas de resultados.

Admitamos de partida que o conjunto das empresas integrantes do setor tradeables se mostre capaz de produzir, com qualidade e preço competitivo, um bom número debenseserviçostípicosda atualidade. Em setratando deeconomias recentementeindustrial izadas, isto significa quea economiajá percorreu o caminho da replicação: produzir - o mesmo - tornou-se para ela trivial.

D adaacompetênciaadquirida para produzir, enamedida em queaeconomia seja submetida à severa prova da competição internacional, começa a ganhar relevância a capacitação para introduzir variações- seja nos produtos levados ao mercado, seja na própria forma de inserção no mercado. D esponta assim, como objetivo, um novo tipo de mudança. Para caracterizá-lo convém recorrer a uma sumária comparação.

Seo primeiro enfoque(dasfalhas demercado) admitetacitamenteasimetria 
das posições individuais e privilegia categorias universais como o ótimo; se 0 segundo põe em destaque os padrões e as regularidades setoriais; com o terceiro ganham relevância as especificidades das empresas. M ais precisamente, salta para o primeiro plano o que lhe é peculiar. É com isto que contam os centros de decisão para, frenteà pressão dos competidores, cultivar diferenças, criar edefender posições. E por centros de decisão entendemos aqui, fundamentalmente, as empresas singulares, mas, também, para certos efeitos, associações de empresas, parcerias, redes, ou clusters.

Fica pois claro que o tipo demudança privilegiado nestaterceira abordagem é aquele capaz de, em al guma medida, e por al gum tempo, isolar a empresa dos rigores e extremos da plena e indiferenciada exposição à competição. ${ }^{5}$ Genericamente a mudança se corporifica, na adoção de inovações. Contemporaneamente, ena prática, contudo, isto requer o desenvolvimento de diversas funções corporativas, praticamente inexistentes, seja na empresa manchesteriana, seja, mesmo, na empresa fordista. A partir da microproteção criada pelo isolamento acima referido (um equivalentefuncional das patentes), as empresas podem ter o seu retorno ampliado. Surge assim a figura da "renda", que alimenta o crescimento (ajudando a direcioná-lo), permite financiar novos esforços visando levar adiante a própria diferenciação, bem como possibilita o pagamento demelhoressalários.

É fácil perceber quea partir desta perspectiva, tão ou maisimportanteque diagnosticar as deficiências e distâncias em relação ao existente nas áreas desenvolvidas, émapear aquilo com quese podecontar para continuar avançando. Assim sendo, cabeinsistir em quea comparação deve contrapor, prioritariamente, a empresa consigo mesma; ou seja, a capacitação, comprovadamente existente, com a que se pode, presumivelmente, al cançar. A categoria básica deixa portanto de ser 0 atraso, e passa a ser o potencial.

N esta mesma linha de análise ganham importância as assimetrias, bem como as eficiências (ou mesmo ineficiências) excepcionais. É, pois, necessário, liberar-se da tradição vinda do paradigma setorial - que abafa ou anula a sensibilidade para o idiossincrático. Afinal, em vez de replicar (e, portanto,

\footnotetext{
5 Ver o conceito de "isolating mechanism" em Rumelt (1997).

${ }^{6}$ O conceito de renda aqui utilizado foi definido por Rumelt (anteriormente citado) como "lucros que não atraem nova produção" (Montgomery, 1977).
} 
convergir) há agora que cultivar as diferenças. E, para tanto, o importante são as possibilidades percebidas pelos que decidem. Setor, em contraposição, não decide. Além disto, e como já foi assinalado, as suas referências estão fora, naquilo que pode ser observado em outros contextos, servindo, portanto, para apontar aosiniciantes, a "imagem do seu próprio futuro". Agora, porém, setor conta, basicamente, na medida em que se distingam as armas da competição tipicamente empregadas pelas empresas que o integram.

0 tema que está aqui sendo levantado ganhou especial relevância com a rápida abertura de diversas economias nos últimos dez a vinte anos. Em certos casos, reconhecidamente, rápidas mudanças foram levadas a efeito, em resposta à abertura. $M$ as não se pode propriamente afirmar que as empresas se guiaram pelos sinais de mercado, na sua vigorosa reação. Esta suposição seria, aliás, particularmente equivocada, ali onde, a exemplo do ocorrido no Brasil, elas basicamente se mantiveram fiéis às suas rotas setoriais e trajetórias tecnológicas (C astro, 2001). Em tais casos tudo se passa como se importantes possibilidades latentes nas empresas tivessem sido reveladas através de uma profunda eabrangente operação de inspiração penrosiana.

A agenda de políticas públicas consistente com o que precede parte, por definição, do apoio à empresa (ou combinação de empresas) nos seus esforços em buscada variedade I sto inclui ou seestende, naturalmente, numa direção inexistente na fase de recuperação do atraso: a biodiversidade empresarial deve ser assumidamentecultivada.

M as é preciso desde já advertir que estamos falando, fundamentalmente, de deslocamento do foco. Vale dizer, o que precede não implica afirmar que devam desaparecer, interramente, certosobjetivos privilegiados pelas políticas de resultados. Assim, excepcionalmente, um setor com elasticidaderenda muito elevada ou, presumivelmente, dotado degrandes efeitos derrame(spillover), pode vir a ser al vo de múltiplo apoio. M as estetipo de iniciativa ou programa deveser entendido como efetivamente residual. ${ }^{7}$

\footnotetext{
7 Na seção dedicada ao Brasil será feita referência às políticas de apoio às exportações.
} 
A pontados al guns traços ou noções preliminares, acerca daterceirafamília de políticas voltadas para o lado real da economia, tratemos de caracterizá-la.

Como vimos anteriormente as políticas de recuperação do atraso requerem a coordenação prévia de certas decisões queen volvem diferentes atores, equepodem ser consideradas críticas ou fundamentais para o avanço em direção aos grandes resultados pretendidos. Comparativamente, no entanto, na criação de novidades a interdepen dência de decisões é ainda maior - e mais difícil de coordenar. É que para chegar a novidades são possivelmente necessários conhecimentos ainda não existentes. 0 u seja, não há apenas um gap de coordenação das decisões diretamente relacionadas com os novos empreendimentos, mas, também, um gap de conhecimento. Isto significa que há que se preocupar com passos anteriores às decisões empresariais. Refiro-me ao esforço múltiplo visando a geração dos conhecimentos e das informações requeridas pelo avanço pretendido.

Em suma, ressalvadas certas inovações incrementais, há poucas chances de que o candidato a inovar seja também capaz de gerar os conhecimentos necessários para levar a efeito o seu projeto. E da constatação desta interdependência muito maior resultou a idéia de que as políticas voltadas para a criação do novo requerem a constituição de autênticos sistemas nacionais de inovações (Lundwall, 1992). ${ }^{8}$

Recapitulando, com o advento da terceira etapa, as políticas industriais decortetradicional tendem a refluir para uma posição meramente residual. Ao mesmo tempo ganham espaço as políticas de ciência etecnologia, edeinovação. Aqui passa a situar-se, indubitavelmente, a nova fronteira das políticas que buscam, diretamente, influenciar a tomada de decisões empresariais - e, por conseqüência, a evolução da economia real. Por que? A resposta está contida no texto. Porque enquanto antes se tratava de construir replicando - ou seja, alinhando-se com o existente em outras partes - , agora se trata de explorar 0 desigual, o localizado, eo atéentão não percebido. Para o país como um todo, eespecialmenteno campo manufatureiro, isto implica a crescente superação da divisão internacional do trabalho por setores, e o realce progressivo das trocas intra-setoriais.

8 Para as relações entre políticas de inovação e políticas de ciência e tecnologia, ver Metcalfe (2002). 
É evidenteque se tem muito a ganhar, nesta como na fase de políticas de resultados, com a elaboração de "visões" do futuro pretendido. M as é fundamental perceber que o novo tende a surgir tópica elocalizadamente. Em muitos casos, além disto, o novo vem envolvido na redefinição de estratégias. Por redefinição deestratégias entenda-seaqui a revisão dos efforços de capacitação, a reponderação das atividades e funções compreendidas na empresa, e o seu reposicionamento no mercado - mudanças quepodem chegar a alterar a própria identidade das empresas.

0 anterior pretendehaver deixado claro queas políticas integrantes deste terceiro bloco - não obstante referidas a visões de futuro - são mais leves e propensas à descentralização operacional. Vejamos como as ponderações aqui apresentadas podem ser usadas no exame da evolução recente da indústria brasileira.

\section{Breve referência ao caso brasileiro}

0 estado atual da indústria no Brasil podeser considerado frustranteem vários sentidos.

0 crescimento médio tem sido da ordem de $2 \%$ ao ano, o que dispensa comentários. Não se consegue conjugar produção (realizada no âmbito das empresas) e geração de novos conhecimentos - que permanece, segmentada, nas Universidades e Centros de Pesquisa. A estrutura industrial encontra-se desfalcada de diversas atividades, situadas na fronteira da evolução tecnológica mundial. E, há, por fim, o grande vilão: o pífio desempenho das exportações de produtos industrializados, em flagrante contraste com o ocorrido nas economias de crescimento acelerado.

Este conjunto de frustrações leva de imediato a pensar em políticas industriais "de resultados". E não é por outra razão que a recente retomada do debate sobre política industrial, começou centrada neste tipo de proposta.

Apesar de partir da verídica constatação de graves problemas, esta abordagem deve, porém, ser criticada sob vários ângulos. Vejamos porque.

O G ráfico I deixa claro que a indústria teve, no passado recente, um comportamento extraordinariamente instável. Por quatro vezes 0 impulso 
expansionista foi de tal ordem que o crescimento da indústria, anualizado, ultrapassou 7\%. Por contraste com esta exuberante conduta, no entanto, por três vezes as atividades industriais desabaram: retraindo-se a uma velocidade, anualizada, de mais de 4\%, em duas ocasiões, e quase a este ritmo no ano de 1999. V ista a questão por este prisma, aliás, o medíocre crescimento médio do período, da ordem de $2 \%$ ao ano, pouco ou nada significa ou representa.

\section{GRÁFICO I}

Indústria geral sem ajuste sazonal - variação percentual

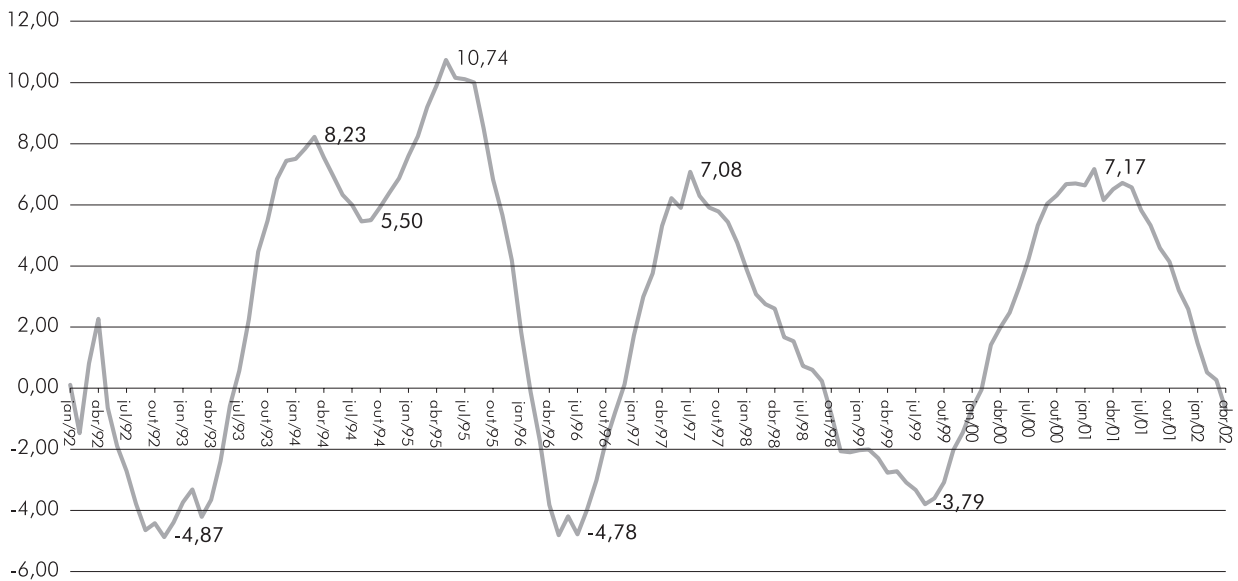

Fonte: PIM, IBGE, elaboração do Grupo de Conjuntura, Instituto de Economia, UFRJ.

É importante assinalar que, ao contrário das recaídas, os vigorosos repiques da atividademanufatureira não devem ser entendidos como resultado de políticas de estímulo à economia. Basta ver, aliás, que os juros reaismédios, de 1994 até o presente, e mesmo depois das reduções ocorridas após a desvalorização, foram sempremantidosem níveis elevadíssimos em comparações internacionais. Concretamente se pode, pois, afirmar, que a economia - e a indústria, muito particularmente- têm sido permanentementetravadas. ${ }^{9}$

Por outro lado, e esta é uma característica maior da moderna economia brasileira, o exterior jamais puxou para cima o nível de atividades. Em outras palavras, a energia da retomada tem sido estritamente endógena- ao contrário

\footnotetext{
9 Convém lembrar, no entanto, que do lançamento do Real até a segunda metade de 1998 a política fiscal foi sempre frouxa - em flagrante conflito com a política de juros, e deixando clara a duvidosa consistência do regime de políticas macroeconômicas (Giambiagi, 2002).
} 
do ocorrido em tantos outrosmercados emergentes. M as o seu fôlego (demédio elongo prazos), como assinala o $\mathrm{G}$ ráfico I, não chega sequer a ser testado. $\mathrm{N}$ as retrações, sim, têm prevalecido os impulsos negativos oriundos de fora - e amplificados por políticas governamentais de natureza pró-cíclica.

0 anterior sugere claramente que o decepcionante comportamento da indústria nos últimos anos não revela ausência de dinamismo próprio. M ais queisto, deixa no ar uma intrigante questão: que resultados, afinal, poderiam ser obtidos por eventuais políticas de apoio à indústria, numa economia freqüentemente submetida à asfixia de demanda? Parecesensato admitir que os resultados só mudariam se o dinamismo das exportações (e, secundariamente, da substituição de importações) fosse capaz de remover as dificuldades externas - e, conseqüentemente, destravar a economia. Isto nos faz sal tar para a última dasquestõesacimalevantadas.

O s dados indicam, por mais de um ângulo, que a sobrevalorização cambial, no período 1994 a 1998, seriamente comprometeu o desempenho exportador da indústria. Assim, por exemplo, se no período 1990 a 19940 número de empresas exportadoras cresceu 13,8\% ao ano, de 1994 a 1998 este mesmo número estagnou.

O corre, porém, quea desvalorização de 1999 tampouco acarretou grandes resultados. $\mathrm{E}$ isto remete a um amplo e inconcluso debate sobre 0 comportamento das exportações ( $M$ arkwald, 2001, 2002). 0 tema será, porém, aqui considerado, unicamente em função da questão das políticasindustriais. $\mathrm{E}$ para tanto faremos, de início, uma sumária recapitulação do ocorrido com a indústria a partir da abertura.

D iante do desafio colocado pelo aumento gal opante das importações, certas linhas de produtos, seções, edepartamentos foram eliminados, com ou sem out-sourcing. Em algumas empresas, porém, logo é percebida a possibilidade de um tratamento evolucionista - enão mais (apenas) cirúrgico. Trata-se, em suma, de trazer à tona possibilidades até então não exploradas. Gosto de citar, a este propósito, a declaração de um industrial de que nos anos dealta inflação muitas empresas haviam entrado em "hibernação". C om a abertura ea estabilização era chegada a hora de sair deste estado, atualizandoseo potencial existente- freqüentementecom o auxílio de (novas) importações (C astro, 2001). 
Em última análise estamos aqui nos referindo a um reposicionamento estratégico. 0 srecursosacumulados pelasempresas foram reavaliados, buscandosedefinir que novos serviços produtivos poderiam ser deles extraídos, demaneira a obter-se - com a ajuda de importações e a aquisição de conhecimentos produtos similares aos importados. Além disto, os produtos (novos ou não) a serem aqui produzidos, não poderiam ser vendidos no mercado doméstico, a preços superiores aos do similar procedente do exterior. Em muitos casos isto impunha substanciais rebaixamentos de preços, colaborando, assim, para a ampliação dosmercados domésticos.

Genericamente falando, o êxito al cançado nesta reconversão não é mais hoje, objeto decontrovérsias. Primeiramente, no sentido dequeum grandenúmero de empresas passou de fato a contar com plantas atualizadas, a praticar formas contemporâneas degerenciamento, ea lançar no mercado produtosatualizados. Completa o êxito, o fato de queantesmesmo da desvalorização cambial dejaneiro de 1999, começava a desaparecer a ameaça de crises setoriais, advindas datomada dosmercados locais por artigosimportados. É bem verdadequeem determinados casos - ZonaFranca de $M$ anaus, acordo automotivo e certos programas deapoio creditício - a mão visível do Estado deu uma substancial ajuda. M as isto não nega o fato de que estas intervenções tópicas ocorriam simultan eamente com 0 avanço febril do movimento de reestruturação. Finalmente, como bem se sabe, uma insuspeitada sucessão de desvalorizaçõesem 2001 e2002, eliminou qual quer ameaça aos produtores locais, por parte das importações.

Podemos agora retomar a pergunta que deu origem a esta digressão - e que, como veremos, tem tudo a ver com o ingresso no terceiro padrão de políticas voltadas para lado real da economia. Em suma, por que, afinal, 0 decepcionante desempenho exportador?

$\mathrm{H}$ á diversas respostas, parcialmente verdadeiras, para esta questão ( $M$ arkwald, 2001, 2002). Tenho defendido quea melhor forma de entender 0 fenômeno éatentar para as opções estratégicas realizadas pelas empresas, frenteà abertura. Em suma: no esforço para sobreviver à ameaça das importações, as empresas aqui sediadas reagiram fortemente, priorizando, claramente, as questões operacionais. Além da modernização gerencial, dedicaram-sea atualizar aslinhas de produtos e a alterar os processos produtivos, tanto quanto necessário para a replicação local de produtos mais avançados. 0 êxito desta empreitada logo se 
traduziu em relativa excelência fabril, característica que continuaria sendo aprimorada, mediantea incessantetroca de equipamentos. Assim respondendo a um questionário no último trimestre de 2001 , "apenas $13 \%$ consideram-se tecnologicamente 'menos avançadas' ou 'muito menos avançadas', comparativamente a seus competidores" ... "A introdução denovos produtosfoi a principal estratégia denegócios priorizada pelo setor industrial na segundametade dosanos 1990, indicada por 70\% das empresas" (FIN EP/CNI, 2002).

Em resumo, a estratégia deproduzir "artigossimilaresa preçoscompetitivos", foi levada a bom termo. I sto, porém, genericamente falando, não era o bastante para penetrar nosmercadosexternos. $\mathrm{O} u$, dito de outra maneira, "elas (asempresas) não se encontram preparadas para colocar os seus produtos além do mercado doméstico" ... "que permanece como o seu habitat preferido" (C astro, 1998).

$\mathrm{N}$ a raiz do problema encontra-se uma insuficiência herdada do período de proteção ealta inflação. N ão setratava debaixa capacitação para produzir, como pretendiam os críticos do chamado modelo de substituição de importações. 0 problema consistia em quea proteção ea alta inflação permitiam queos produtores pouco esforço fizessem para conquistar os consumidores. $\mathrm{N}$ ão era preciso ir atrás do peixe: elepróprio entravana rede. Isto prosseguiu durantetodaa alta inflação - enão chegou a ser superado, mesmo com a reestruturação detonada pelaabertura. Afinal, para disputar o mercado doméstico, mostrou-se suficiente oferecer artigos similares aos importados, a preços competitivos. N uma palavra, os produtores locais em grandemedida continuavam despreparados para disputar mercadoscom as modernas armas da competição: não vendem, são comprados, na expressão cunhada por produtores gaúchos decalçados.

N os mercados centrais, contudo, os "novos" artigos aqui produzidos são produtos atualizados, porém "maduros". O s respectivos mercados tipicamente não maiscrescem - eseencontram pressionadas por ofertantes de todo o mundo. Aí oscompradores, efetivamente, ditam as regras.

Voltando às empresas reestruturadas, dá, em suma, para disputar o mercado interno - que não é sobre-ofertado, e nem muito exigente em qualidade. No mercado externo, contudo, só é possível expandir as vendas dos produtos que passamosrecentementea produzir (sobretudo sese preten defazêlo rapidamente) mediante preços contundentemente baixos, ou através do emprego competente demodernas armas da competição. Entreelas, destacadamente, a introdução de 
propriedades diferenciadas (inclusive design), poderoso marketing, marcas, ou inserção em cadeias locais.

Genericamente, contudo, as empresas nacionais não se encontravam preparadas, nem para "comprar mercado", nem para lançar mão das modernas armas da competição. Seu principal trunfo continuava sendo, ressal vadas exceções, como a EM BRAER, a excelência operacional. Esta proposição, contudo, não se aplica às filiais de multinacionais aqui sediadas - que podem colocar "produtos mundiais" nos mercados centrais, e têm a seu dispor as modernas armas da competição. $\mathrm{N}$ ão deve pois surpreender a conclusão de um estimulante estudo recentemente publicado, segundo o qual "A probabilidade de uma firma multinacional exportar é $700 \%$ maior que a de uma firma nacional"(Arbache, D eN egri, 2001).

A inusitada desvalorização cambial de2002 eo recrudescimento daspolíticas convencionais de exportação facilitam hoje, no entanto, o primeiro canal de acesso: a compra demercado. Somentea criação devariedadeseo desenvolvimento de produtos, permitirá, porém, ao longo do tempo, uma inserção mais empreendedora emenosvulnerável.

Vimosanteriormentequeas políticas públicas integrantes do terceiro bloco buscam ajudar a empresa a avançar na produção devariedades. D evem, paratanto, empenhar-se na criação desistemasnacionais de inovação, cultivar a emergência denovosempreendimentos, bem como apoiar, seletivamente, a (re)definição de estratégias. Acrescente-se que o avanço em qual quer destesterrenos tendea ser beneficiado pela formulação de imagens do futuro (visões). Estas ponderações, contudo, não contemplam a especificidade dos casos nacionais. E é para isto que devemos, mais uma vez, momentaneamente nos voltar.

Para competir no mercado doméstico pós-abertura, as empresas brasileiras promoveram intensa racionalização eatual ização de seus porta-fólios deprodutos. Trataram para tanto de explorar o potencial contido nos recursos por elas controlados, visando lançar em mercado, fundamentalmente, o queestava sendo demandado, na onda da abertura. M as é importante frisar que não se tratava, propriamente, deuma operação penrosiana. Asescolhaseram predominantemente 
técnicas (como lograr produzir $X$, com os recursos disponíveis, acrescidos de importações), enão propriamenteempresariais (o queproduzir denovo, dadasas possibilidades entreabertas pela evolução da capacitação, e as possibilidades vislumbradasno mercado).

Frente a esta acomodação inicial, o ingresso ulterior na produção de variedades apresenta, presumivelmente, duas etapas. Primeiramente, trata-se de descobrir o que de melhor se pode fazer, empresarialmente, para definir um novo "corebusiness", baseado em variedades próprias, enão na mera capacidade de replicar o similar importado. Além disto, há que assumir (tornar sistemática) a pré-disposição ou atitude inovadora - e isto requer o aprofundamento das relações com o nascentesistema nacional deinovações.

A primeira etapa busca, em última análise, apurar a pontaria. A segunda envolve a redefinição das identidades das empresas, e o desenvolvimento das modernas armas da competição - bem como das relações com a infra-estrutura voltada para a inovação. É de interesse das empresas queas duas etapas avancem praticamentejuntas. $D$ equalquer forma, ao fornecer múltiplo apoio a estetipo de evolução, as políticas estarão ajudando a alcançar retornos-prêmio, não obstante paguem, possivelmente, salários-prêmio. 


\section{Bibliografia}

Amsden, Alice, The Rise of The Rest, Oxford University Press, 2001.

Arbache, Jorge; De N egri, João Alberto, D eterminantes das Exportações Brasileiras: N ovas Evidências (mimeo), Universidade de Brasília, nov., 2001.

Bhagwati, Jagdish, "The Generalized Theory of Distorsions and Welfare", in

Bhagwati, J. et al. (eds.), Trade, Balance of Payments and Growth: Papers in Honour of Charles Kindleberger, North H olland, 1971.

Brasil. M inistério da Ciência e Tecnologia. A Indústria e a Q uestão Tecnológica, FIN EP/CNI, 2002.

Castro, Antonio Barros, "C rescimento Rápido Versus Balança de Comércio como Variável de Ajuste". In João Paulo dos Reis Velloso (org.), 0 Brasil e o M undo no Limiar do N ovo Século, José O lympio, 1998.

"A Reestruturação da Indústria Brasileira nos anos 90: uma Interpretação". Revista de Economia Política, jul./set., 2001.

Chang, Ha-Joon, The Political Economy of Industrial Policy, M acmillan, 1994.

Foss, Nicolai, Resources Firms and Strategies, O xford University Press, 1997.

Gerschenkron, Alexander, "Reflections on the Concept of 'Prerequisites' of M odern Industrialization", in Economic Backwardnessin H istorical Perspective, The Belknap Press, H arvard U niversity Press, 1966.

Giambiagi, Fabio, D o D éficit de M etas às M etas do D éficit: a Política Fiscal do Governo Fernando H enrique Cardoso (mimeo), abr., 2002.

Lazonick, William, "Social O rganization and Technological Leadership". In Baumol, William et al., Convergence of Productivity, Oxford University Press, 1994.

Lundwall, B.A., N ational Systems of Innovation: towards a theory of Innovation and Interactive Learning, Pinter, 1992.

M arkwald, Ricardo, Focando a Política de Promoção de Exportações. FU N CEX, jul., 2002.

"O Impacto da Abertura sobre a Indústria Brasileira", in João Paulo dos Reis Velloso (org.), Como Vão o D esenvolvimento e a D emocracia no Brasil?, Rio de Janeiro: José O lympio, 2001. 
M etcalfe, Stanley J. , "Evolutionary Economics and Technology Policy", TheEconomic Journal, v. 104, 1994.

Equilibrium and Evolutionary Foundations of Competition and Technology Policy: N ew Perspectives on the Division of Labour and the Innovation Process Texto apresentado no Workshop "Frontiers and Trends of Innovation Policy", Rio de Janeiro, 2002.

M ontgomery, Cynthia; Wenerfeld, Birger, in "Diversification, Ricardian Rents, and Tobin's q". In Foss, op. cit.

Nelson, Richard; W inter, Sidney, An Evolutionary Theory of Economic Change, H arvard University Press, 1982.

Penrose, Edith, TheT heory of the Growth of the Firm, O xford U niversity Press, 1959.

Richardson, G.B., Information and Investment, anexo II. Clarendon: O xford, 1997.

Rumel, Richard, "Towards a Strategic Theory of the Firm" in Foss, op. cit.

Vartiainen, Juhana, "The Economics of Successful State Intervention in Industrial Transformation", in WooCumings, M eredith (ed.), The D evelopment State, Cornell University Press, 1999. 